Unicum $\delta$ indiviảum die 21. Aprili mense anno 1878 apud urbem Novorossijsk a me lectum est nunc in honorem professoris illustrissimi Ernesti Ballionis, quo magistro in re entomologica usus, maximas ei gratias debeo, nominavi Phyllobium Ballionis.

3. Rhynchites parellinus Gyll. var. nova fallax mihi.

Coeruleus aut viridis, nitidus. Corpore toto supra raris longisque infra densis brevioribusque pilis nigris obtecto. Habitu communi Rhynchiti parellino similis, distat autem crassiore et breviore rostro, cujus longitudo minor, quam capitis thorace addito. L o n g., rostro excepto, $4-5 \mathrm{~mm}$, la t. ad humeros $2-3 \mathrm{~mm}$.

Haec varietas mensibus Aprili et Majo annis 1874-78 apud Novorossijsk urbem a me collecta est.

\title{
Tres novae varietates Carabitarum in Cancaso occidentali
}

repertae ab Alexandro Starck in Utsch-Dere ab eoque descriptae.

1. Cechenus Boeberi Ad. var. nova Heydenianus mihi.

Habitu generali Cecheno Boeberi vero similis; supra niger aut nigro-viridis, elytrorum thoracisque margine viridi, tenuibus punctis in elytris tribus seriebus regularibus impressis; femora, apicibusexceptis, coxae trochanteresque rufa, antennarum articuli primi, tres sequentes medii et apicesultimorum articulorum palporum eodem colore gaudent. Long. $17 \mathrm{~mm}$.

Nonnulla exemplaria hujus varietatis mense Julio 1888 anni a me in monte Dsitaku, Caucasi occidentalis, in altitudine prope novem millia pedum sunt reperta.

Varietatem hane illustrissimo viro L. de Heyden dedico. Unum exemplarium museo caesareo Viennensi tradidi.

2. Neoplectes Riedeli Mén. var. nova convallium mihi.

Iam anno 1879 ac insequentibus in convallibus UtschDere nonnulla splendida exemplaria Plectis cujusdam cepi, quae ab illustr. de Heyden ut cupreus Chaud. determinata sunt (vide Wiener Entom. Ztg. IV, 1885, pag. 189). Iam illustrissimus ille $\mathrm{H}$ eyden haec exemplaria colore esse diverso notavit, quam illa a $\mathrm{Chaudoir}$ descripta. Postea illustris Custos-adjunctus musei caesar. Viennensis dom. Gangl-

Wiener Entomologische Zeitung, VIII. Jahrg., 2. Heft (28. Februar 1889). 
bauer nonnullis exemplaribus attente convisis ac perscrutatis cupreum Chaud. nihil aliud esse nisi Riedeli Mén. invenit, et descriptionem accuratam hujus speciei suo operi "Revision der kaukasischen Plectes- oder Tribax-Arten", inseruit (vide Deutsch. Ent. Zeitschr. 1886, pag. 313). Postea multa individua hujus speciei collegi in regione alpestri montium Caucasi occidentalis, quibus comparatis cum in convallibus collectis mihi persuasi haec ab illis colore ac habitu generali distare. Exemplaria montana proxime ad descriptionem Ménétries et $\mathrm{C}$ h a u d o ir accedunt, quam ob rem veram Plectis Riedeli formam montanam judicandam video, nam ipse M énétries Plectem hunc prope ad nivalem regionem reperit.

Neoplectes Riedeli Mén. (montanus): supra cupreus, elytris brevi-ovatis, leniter ad posticum dilatatis, dense et fortissime punctatis. Habitat in altis solum montibus.

Neoplectes Riedeli Mén. var. convallium mihi: supra viridis aut viridi-aureus, elytris oblongo-ovatis, ut latitudo maxima sescuplam facit latitudinem humerorum, leniter striatis, lenius et rarius punctatis. Magnitudine quoque haec varietas veram speciem antecedit. Habitat in convallibus Caucasi occidentalis usque ad ipsum Ponti Euxini litus descendentibus.

Nonnulla exemplaria museo caesar. Viennensi tradidi.

Notatu dignum esse mihi videtur regione media inter oram maritimam ac altissimos montes neutram formam nec Riedeli neve convallium reperiri posse. Hoc quidem differentiam speciei ac varietatis augeri arbitror.

3. Neoplectes obtusus Ganglb. var. nova Adelaidae mihi.

Habitu generali verae formae speciei similis, ut ab illustrissimo domino Gang $\mathrm{l}$ ba uer descripta est in „Deutsch. Ent. Zeitschr." 1886, pag. 319, sed supra viridis aeneo-micans, thorace lenius punctato et ad margines leniter rugoso. Lon g. $26 \mathrm{~mm}$ (exempl. formae speciei verae assequitur $32 \mathrm{~mm}$ longit.).

Unus ô hujus varietatis a me captus est Junio mense anno 1887 i regione silvestri prope 5000 pedum alta saltus Atschischcho Caucasi occidentalis eumque in honorem uxoris meae, quae assiduum ac continuum auxilium mihi in operis entomologicis praebet, nominavi.

Hoc unicum individuum museo caesar. Viennensi misi. 


\section{$2 \mathrm{BHL}$ Biodiversity Heritage Library}

Stark, Alexander Alexandrovich. 1889. "Tres novae varietates Carabitarum in Caucaso occidentali." Wiener entomologische Zeitung 8, 55-56. https://doi.org/10.5962/bhl.part.20024.

View This Item Online: https://www.biodiversitylibrary.org/item/42656

DOI: https://doi.org/10.5962/bhl.part.20024

Permalink: https://www.biodiversitylibrary.org/partpdf/20024

\section{Holding Institution}

Smithsonian Libraries

\section{Sponsored by}

Smithsonian

\section{Copyright \& Reuse}

Copyright Status: NOT_IN_COPYRIGHT

This document was created from content at the Biodiversity Heritage Library, the world's largest open access digital library for biodiversity literature and archives. Visit BHL at https://www.biodiversitylibrary.org. 